\title{
A generalized model for financial time series representation and prediction
}

\section{Depei Bao}

Published online: 10 November 2007

(C) Springer Science+Business Media, LLC 2007

\section{Erratum to: Appl Intell}

\section{DOI 10.1007/s10489-007-0063-1}

The following co-authors names were inadvertently omitted from this article:

\section{Zehong Yang}

State Key Lab of Intelligent Technology and Systems Department of Computer Science Tsinghua University, Beijing, China 86-10-62796828

yangzehong@ $@$ tsinghua.org.cn
Yixu Song

State Key Lab of Intelligent Technology and Systems Department of Computer Science Tsinghua University, Beijing, China 86-10-62796826

sonyixu@sohu.com

The online version of the original article can be found under doi:10.1007/s10489-007-0063-1

D. Bao ( $\varangle)$

Tsinghua University, Beijing 100084, China

e-mail: baodepei@gmail.com 